\title{
Idārat Jūdat al-Ishrāf al-Lughawiy fi Tarqiyat Ta'līm al-Lughah al-'Arabiyah bi Ma'had Jāmi'ah Maulāna Mālik Ibrāhīm al-Islāmiyyah al-Ḥukūmiyyah Malang
}

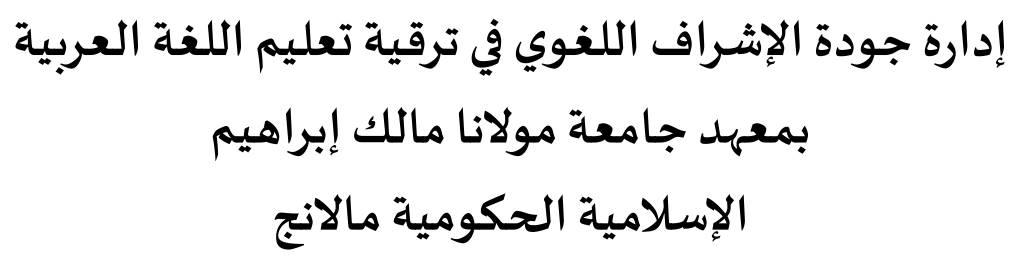

\author{
Bahroin Budiya \\ Universitas Islam Malang \\ Corresponding author: bahroinbudiya@unisma.ac.id
}

\begin{abstract}
There is quality management with education subject who teach and guide college students in Arabic learning. Mushrifs is the santri's companion in the first and second semester in Mahad Al-Jami'ah. In particular program, they teach Arabic in Mahad and conduct Arabic learning. The quality of Mushrifs of Language in improving Arabic learning is one of the objectives in order to generate good and success mushrifs in Mahad Al-Jami'ah. The research problems were: 1) How is the planning quality of language guidance in improving Arabic learning in mahad al-jami'ah, 2) how is the organization quality of language guidance in improving Arabic learning in mahad al-jami'ah, 3) how is the implementation of quality Supervision of language in improving the Arabic learning in mahad aljami'ah, 4) how is the supervision quality of language guidance in improving Arabic learning in mahad al-jami'ah. This study aimed to describe the planning, organization, implementation, and supervision of quality management of mushrifs in improving the Arabic
\end{abstract}

ISSN 2622-6146 (e) 2622-6138 (p)

(C) 2019 Alsina : Journal of Arabic Studies

http://journal.walisongo.ac.id/index.php/alsina 
learning in Mahad Al-jam'ah. This study used descriptive analysis design, and the data collections were through observation, interview and documentation, and through all those things to research in data's about the quality management of language guidance. The results of quality management of language guidance study in improving the Arabic learning were: 1) in the planning stage, the first process was opening the registration for mushrifs' candidates with a very strict selection, 2) in the organization aspect was the cooperation relationship between the mahad director, murabbi, and mushrifs of language with their tasks, 3) in the implementation aspect was through PSDM, language enrichmen, shabah al-lugah, gebyar bahasa competition and bilingual seminar; 4) and in the supervision aspect was the supervision was conducted once in two weeks by murabbi of language.

Pembelajaran bahasa arab di dalamnya terdapat manajemen mutu dengan pelaku pendidikan yang membimbing mahasiswa, Musyrif adalah pendamping mahasantri di semester 1 dan 2 sejak di Mahad Al-Jami'ah. Pada Program tertentu mereka mengajarkan bahasa arab di mahad dan melaksanakan pembelajaran bahasa arab. Manajemen mutu Musyrif bahasa dalam meningkatkan pembelajaran bahasa arab adalah salah satu tujuan untuk menghasilkan musyrif bahasa yang baik dan sukses di Mahad AlJami'ah. Rumusan masalah antara lain: 1) Bagaimana perencanaan mutu bimbingan bahasa dalam meningkatkan pembelajaran bahasa arab di mahad al-jami'ah, 2) Bagaimana pengorganisasian mutu bimbingan bahasa dalam meningkatkan pembelajaran bahasa arab di mahad al-jami'ah, 3) Bagaimana pelaksanaan mutu bimbingan bahasa dalam meningkatkan pembelajaran bahasa arab di mahad al-jami'ah, 4) Bagaimana pengawasan mutu bimbingan bahasa dalam meningkatkan pembelajaran bahasa arab di mahad al-jami'ah. Adapun tujuan penelitian adalah: mendeskripsikan perencanaan, pengorganisasian, pelaksanaan dan pengawasan manajemen mutu musyrif dalam meningkatkan pembelajaran Bahasa Arab di Mahad Al-Jami'ah. Penelitian ini menggunakan penelitian analisis deskriptif, dan teknik pengumpulan data melalui observasi, wawancara dan dokumentasi, dan melalui tersebut untuk menganalisis data tentang manajemen mutu bimbingan bahasa. Hasil penelitian Manajemen mutu bimbingan bahasa dalam meningkatkan pembelajaran bahasa arab yaitu: 1) dari aspek perencanaan bahwa prosesnya adalah membuka pendaftaran bagi calon musyrif dengan selesksi yang sangat ketat melalui ujian seleksi, 2) dari 
aspek pengorganisasian adalah hubungan kerjasama antara Direktur Mahad, Murabbi dan Musyrif bahasa dengan tugas-tugas mereka, 3) dari aspek pelaksanaan melalui PSDM (Pemberdayaan Sumber daya Musyrif/ah), Pengayaan bahasa, shabah al-lugah, lomba Gebyar bahasa dan seminar bilingual, 4) dan dari aspek pengawasan, pengawasan dilakukan 2 minggu sekali oleh murabbi bahasa.

إن تعليم اللغـة العربية فيها إدارة الجودة بالفاعل التربوي الذي يشــرف مشـــف

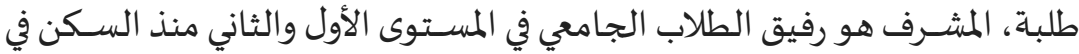
المعهـد، وبرنـامج معين هو يعلّم اللغـة العربيـة في معهـد الجـامعـة وهو ينفـذ تعليم اللغة في ميدان البحث إدارة الجودة لمشــرف اللغة في ترقية تعليم اللغة العربية هي احدى من ألأهداف لحصول مشرف اللغة الجيد والناجح بمعهد الجامعاة. ومشكلة البحث هي: () كيف تخطيط جودة الإشـراف اللغوي في ترقية تعليم اللغة العربية بمعهـد الجـامعـة، r) كيف تنظيم جودة الإثـــراف اللغوي في ترقيـة تعليم اللغــة العربية بمعهد الجـامعـة، ؟) كيف تنفيـذ جودة الإثـــاف اللغوي في ترقيـة تعليم اللغـة العربية بمعهد الجـامعة، ع) كيف مراقبة جودة الإشـــراف اللغوي في ترقيـة

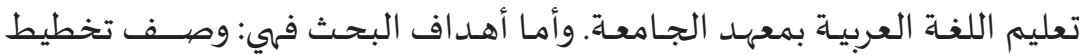
وتنظيم و تنفيذ ومراقبة في إدارتها. يسـتخدم هذا البحث بدراســة وصـفية تحليلية

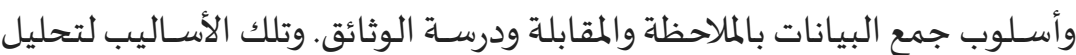

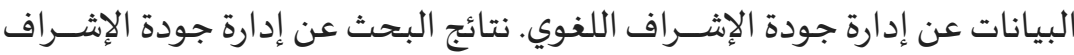

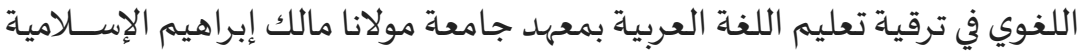

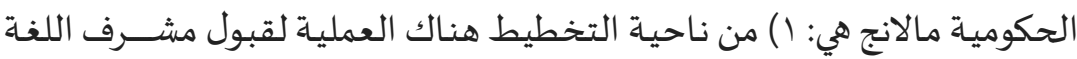
بمعهد الجامعة من جوانب مهارات اللغة والخبرة وارتباط مشــرف اللغـة في تعليم

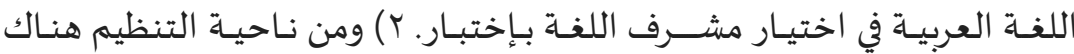
مشاركة مجلس اللغة من مدير معهد الجامعة، ومربي اللغة ومشرف اللغة في ترقية تعليم اللغة العربية. ץ) ومن ناحية التنفيذ بتكوين لمشرف، و عيادة اللغة، وصبباح

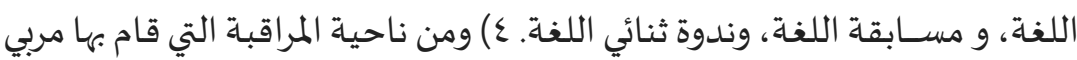
اللغة مرة واحدة في الأسبوعين فيها.

Keywords: Quality Management, Language Guidance, Arabic Learning Improvement. 
Idārat Jūdat al-Ishrāf al-Lughawiy fi Tarqiyat Ta'lìm al-Lughah ...

المقلدمة

من إحدى المؤسسات الإسلامية الحكومية معهد الجامعة الذي يدرس فيـ

الطلبـة الجامعية في جامعة مولانا مالك إبراهيم مالانج، بأن فيـه معهدا يشــرف المشــرف فيه الطلاب على الأنشـــطات وتعليم الدين وتعليم اللغة، قال مدير المعهد أن مزايا إدارة جودة المشـرف في معهد الجامعة يعني له مهارات المتنوعـة، يشـرف المشـرف في مهاراتاه يصــنع المفاهيم والتخطيط في كل أنشــطة لطلاب الجـامعي وبصــفــة مــدرب يـدرب الطلاب لتطوير الكفـاءة والإبتكـارهم على مهاراتهم.' بتســيلات تعليمية مثل كتاب المراقبة يسـهل مشـرفا لقياس تعليم اللغة. وهذا يتجاوز معيار المشــرف بوجه العام، لأن واجبات مشـرف المفروض

لله بمناسبة مجاله فقط. أهمية المشــكلة بإدارة جودة الإشـــراف اللغوي بناء على إختلاف النظرية الموجودة. وكيفية يدير معهد الجامعة لجودة مشـرف اللغة ولماذا هناك إدارة الجودة الذي يقوم بها، في حين أن نظرية معايير مشـرف اللغة بجامعة كلاسـكو الذي يفضل بها هي المهارات اللغوية، والخبرات اللغوية، (glasgow university) والكفاءات اللغوية فيها.` مصــدر القوة لإدارة المشــرف يمكن القيام باه بشـكل جيد لأن هنالك مديرا ومربيا يسـاعدون في تحسـين الأداء والجـودة في تعليم اللغة العربية على وجاه الخصــوص، عملية ترقية جودة في تعليم اللغة العربية يمكن أن تســتمدل من معهد الســلف ومعهـد الحـديث، فإنها وهذا يمكن أن ينظر إليها من قدرة المرءع منهم في تقديم المواد التي يدرس اللغة العربية. قال خير الأديب في مقالتـا تناولت مشـــاكل تعليم اللغة العربية في عام هي عمليـة التعلم أقل جـاذبيـة وتميـل إلى أن تكون مملـة .وذلك لأن نظام التعليم الـذي يميـل للبـدء من قواعـد الترجمـة أو النحوي وتتجــاهـل جوانب أخرى من الاستماع والتحدث والكتابة، رأى القيود على وجـه التحديد على الجوانب منهج

' المقابلة مع إشراق النجاح، (معهد الجامعة، يوم الإثنين هب أبريل 1 ا • ب م)

${ }^{2}$ www.gla.ac.uk/media/media_204791_en, diakses pada tanggal 3 April 2016 
اللغــة العربيـة في المـدارس وتشــــل المــارس الــينيـة: المواد غير مســتقرة، تخصيص الوقت القليل جدا وقدرات طالب غير متجانسـة والخلفيات.

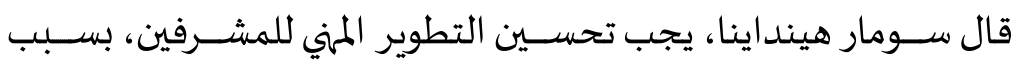

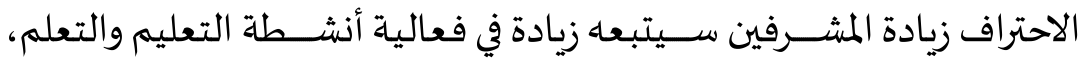

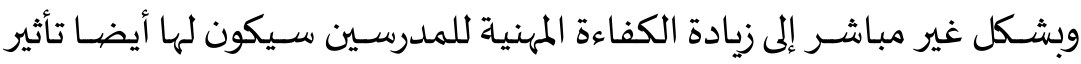
على تحسـين نوعية التعليم بشـكل عام .لذلك، لا بد من دراسـة الدرس الدور. دراسـة الدرس هي عملية تعاونية فيها مجموعات من المدرس على تحديد مشكلة

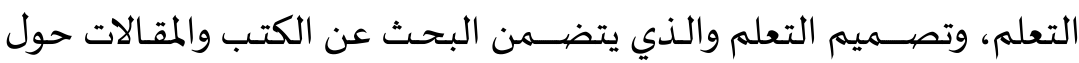

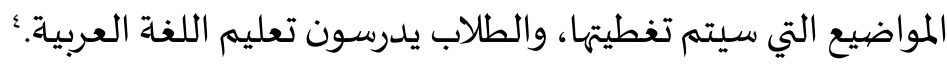
بناء على ذلك، تشجيع الباحث في هذا البحث الذي سوف يهدد ويصيف عن إدارة جودة

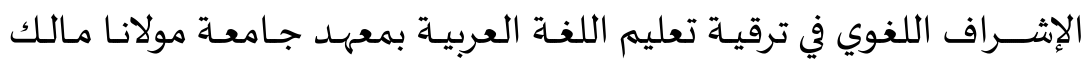
إبراهيم الإسلامية الحكومية مالانج.

\section{مشكلة البحث} وإنّ تفصيل أسئلة هذا البحث كما يلي: أ) كيف تخطيط جودة الإشـراف اللغوي في ترقية تعليم اللغة العربية بمعهد جامعة مولانا مالك إبراهيم الإسلامية الحكومية مالانج؟

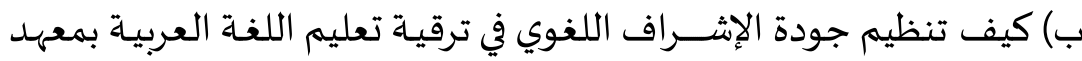

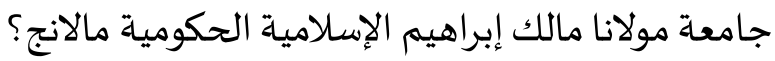

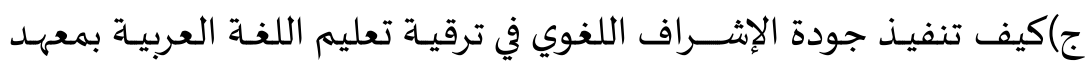

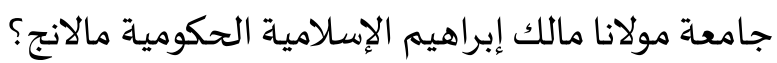

${ }^{3}$ Khoirul Adib , Makalah disampaikan dalam Pelatihan Peningkatan Keprofesionalan Guru Bhs Arab http://sastra.um.ac.id/?p=964 diakses tanggal 22 Nopember 2015.

4 Sumar Hendayana. Dkk. Lesson Study, (Suatu Strategi untuk Meningkatkan Keprofesionalan Pendidik - Pengalaman IMSTEP-JICA. (Bandung: UPI Press. 2007), hlm. 2.

Vol. 1, No. 2 (2019) 
Idārat Jūdat al-Ishrāfal-Lughawiy fi Tarqiyat Ta'lìm al-Lughah ...

د) كيف مراقبـة جودة الإثـــراف اللغوي في ترقيـة تعليم اللغـة العربية بمعهد جامعة مولانا مالك إبراهيم الإسلامية الحكومية مالانج؟

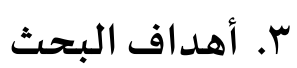

يهدف هذا البحث استنادا إلى ما قد ذكر في أسئلة البحث:

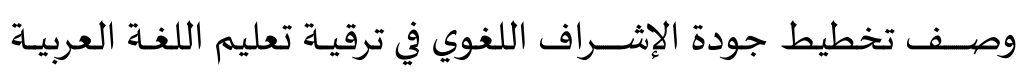

بمعهد جامعة مولانا مالك إبراهيم الإسلامية الحكومية مالانج.

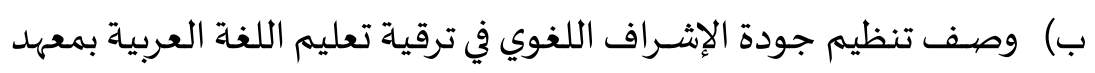
جامعة مولانا مالك إبراهيم الإسلامية الحكومية مالانج.

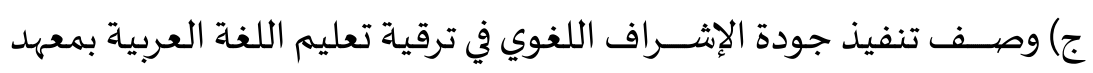
جامعة مولانا مالك إبراهيم الإسلامية الحكومية مالانج.

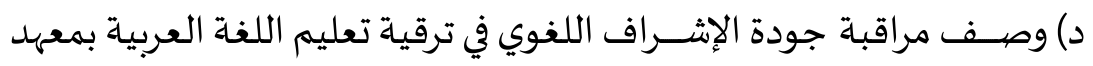
جامعة مولانا مالك إبراهيم الإسلامية الحكومية مالانج.

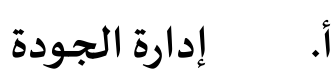

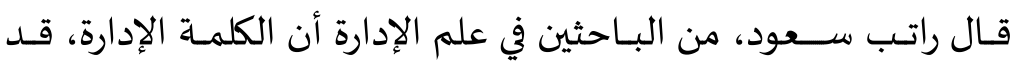
اشـتقت من الكلمة اللاتينية ذات المقطعين، الأول (Ad) والثاني (ministrare)

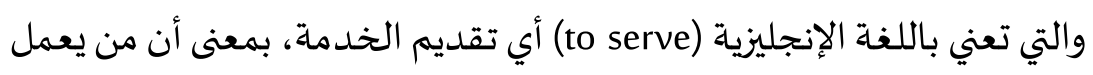

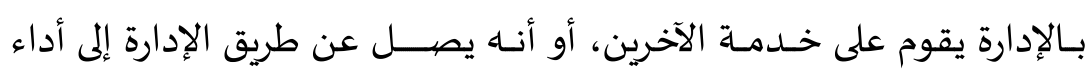

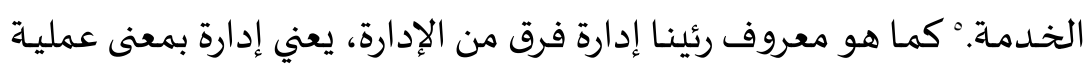

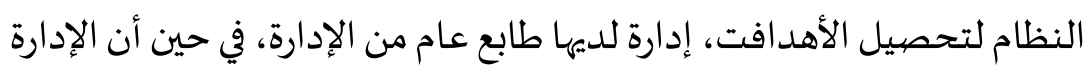

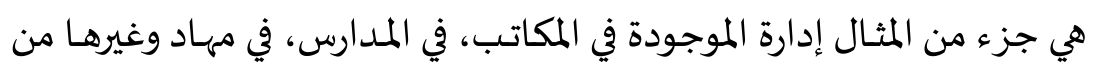

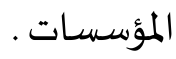

• راتب السـعود، الإشــراف التربوي مفهومه ونظرياته وأسـاليبه، الطبعة الثانية، :

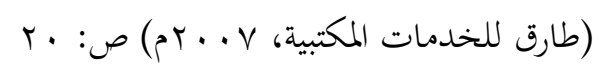


في كتـاب مـارنو أيضــــا قـد يعرفهـا هنري فـايول 9؟9 1، في كتـابـا الإدارة

الصـــــاعيـة والعـامـة من خلال تحـديـده لمعنى أن تـدير، وهو أن تتنبـأ وتخطط وتنظم وتصيدر الأوامر وتنسق وتراقب. وقد عرف بعض الكتاب بأنها "النشـاط الموجـا نحو التعـاون المثمر والتنســيق الفعّـال بين الجهود البشــريـة المختلفـة العـاملـة من أجـل تحقيق هـدف معين بـدرجـة عـاليـة من الكفـاءة. ط والظروف الملائمة والمؤسـســات واحد مفاهيم إدارة مختلفة أخرى، مجرد أن هناك أوجـه التشـاباه والاختلاف في الطريقة العملية للإدارة. 1.

إدارة لها ع فوائد، إدارة الجودة تهدف لإدارة جودة مشــرف اللغـة بطريق

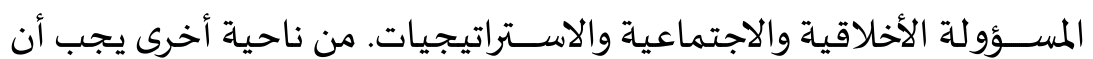
يحقيق التوازن في التنظيمية. أ) التخطيط

عند مالايو هاسـيبون، التخطيط هو تعيين الإحتياجات إما ناحية الكمية

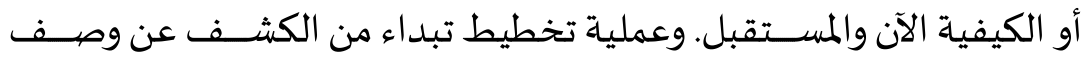
الوظيفة، وهذا تقصــــ لمعرفة أي موقف الحاجـة. والثانية هي تحليل الوظيفة وهـذا تقصـــد لمعرفـة وصــف الوظيفـة يعني الأعمـال المفروضـــة لـدي المعلم. والثالثة هي مواصفة الوظيفة، هذه العملية تتعبر عن أقل جودة المعلمين الذي سيقبل. والرابعة قبول المسسجل. وأهم تلك العمليات هي تحليل الوظيفة.^وقال بجو سيسوانطو، أن قبول المسجل هو عملية بحث الأشخاص و تشجيع الأمل لتسجيل في المؤسسـة.

${ }^{6}$ Marno. Dkk. hlm 21

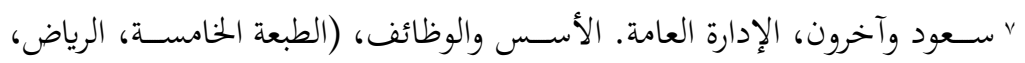

$$
\text { 0: صن (ه) }
$$

${ }^{8}$ Malayu Hasibun, Manajemen Sumber Daya Manusia, (Jakarta: Bumi Aksara, 2000), hlm. 29.

9 Bedjo Siswanto, manajemen tenaga kerja ancangan dalam pendayagunakan dan pengembangan unsur tenaga kerja, (Bandung: Sinar Biru, 1989), hlm. 49.

Vol. 1, No. 2 (2019) 
Idārat Jūdat al-Ishrāf al-Lughawiy fi Tarqiyat Ta'lìm al-Lughah ...

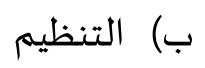

قال مارنو، التنظيم هو عملية تحديد، وتصــنيفـ الواجبـات والمســـؤولية

لأشخخاص، ودسـى بتقسيم أنواع البرامج لحصيسول الهدف. '، وقال عبد الثاني، عمليـة تنظيم هي أهم العمليـة، ومن أهـداف هذه العمليـة هي جودة معلم حتى يكون في الـدرجـة العـاليـة. وفي هـذه المحـاولـة يقوم التـدربــات المنـاســــة على كفـاءتهم كمـا المثـال معلم اللغــة العربيـة يقومون بـالتـدريبـات المتعلقـة بتعليم اللغة العربية. ج) التنفيذ

قال ســــاكيـان، تنفيـذ في إدارة هو بصــفـة محـاولة، وطرائق واســلوب،

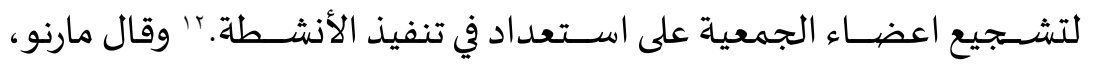
التنفيذ عند كونتز أودونيل في مفهومه، هو علاقة وثيقة بين الجوانب الفردية النـاشــئة عن الاتفاق مع الموظف ليكون قادرا على فهم وفعال تقســيم العمل لتحقيق هدف الشركة الحقيقية. د) المراقبة

قال عرفان فهي، المراقبة هي عملية بما يتعلق لحصــول التحديد وتنفيذ المعايير في تقويم التنفيذ وتحســين حتى مناسـبـة بالتخطيط. ؛ أفي كتاب مارنو، عند جورج تيري صــيـاغـة المراقبـة في محساولة لـدراســـة الأنشــــة التي يتعين الاضـطلاع بها، المراقبة بهدفها الموجهة للضـبط وأداة للتأكد من أن الأشسخاص الذين يعملون لتحقيق هدف المراد تحقيقها. r. الإشراف التربوي

10 Marno. Dkk, Manajemen dan kepemimpinan pendidikan islam, (Bandung: PT Rafika Aditama. 2008), hlm. 16.

${ }^{11}$ Abdul Syani, Manajemen Organisasi (surabaya: Bina Aksara, 1987), hlm .222.

${ }^{12}$ Siagan Sondang, Fungsi -Fungsi Manajerial (jakarta: Bumi Aksara, 2007) hlm 95

${ }^{13}$ Marno. Dk, hlm. 20.

${ }^{14}$ Irfan Fahmi, Analisis Kinerja, (Bandung: Alfabeta, 2011), hlm. 85.

15 Marno. Dkk. HIm 24-25 
إن الإثـــراف التربوي، كغيره من العـديـد من المفـاهيم التربويـة، لم يحظ بتعريف واحد يقبله جميع المختصـيـين. إذ ظهرت مجموعـا من التعريفات التي

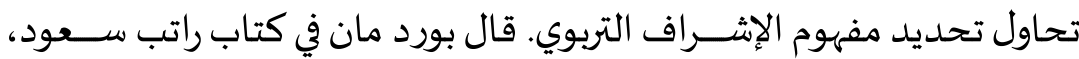

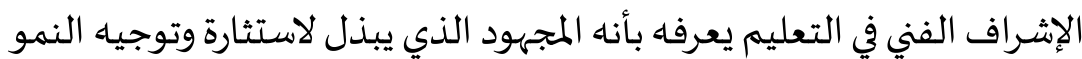
المستمر للمعلمين."17 وبالنضــر إلى هذا التعريف، نجد أن عملية الإشــراف التربوي الفعال تتميز بما يلى: إنها عمليـة تتـألف من مجموعـة من النشـــاطـات التربويـة كالتخطيط والتدريب والتنسيق والتقويم لجميع جوانب العملية التربوية.

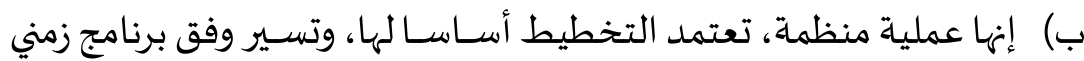

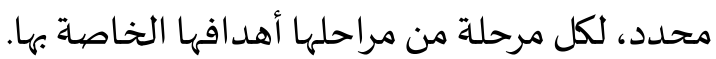

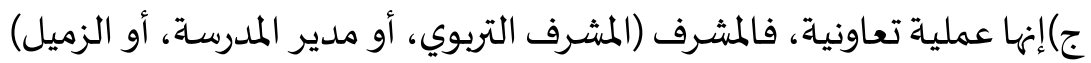

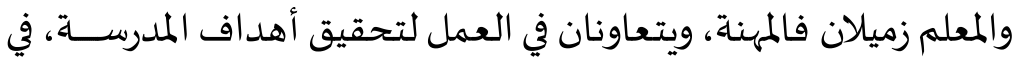
جو من الاحترام المتبادل والتقدير والتقبل

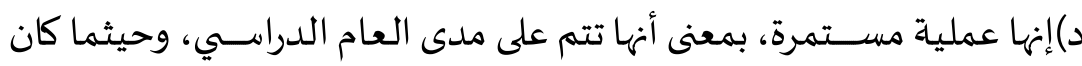
المعلم معلما، وليست متقطعة أو موسمية.

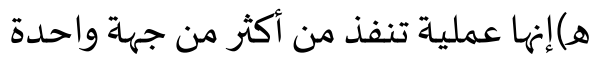

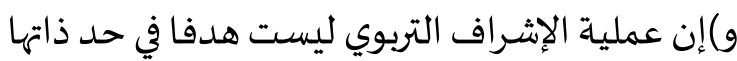

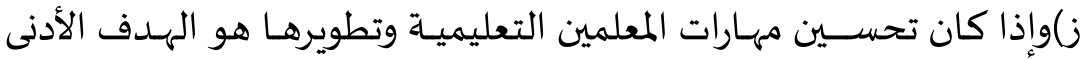

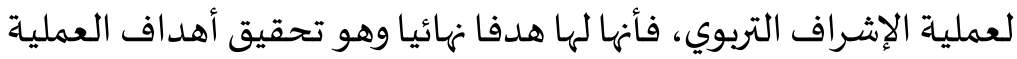
التعليمية أو تحقيق النمو المتكامل للطلبة. 3.

"' راتب السعود، الإشـراف التربوي مفهومه ونظرياته وأسـاليبه، الطبعة الثانية، :

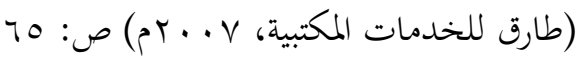

$$
\begin{aligned}
& \text { ע' راتب السعود، ص هی }
\end{aligned}
$$


Idārat Jūdat al-Ishrāfal-Lughawiy fi Tarqiyat Ta'lìm al-Lughah ...

لنجــاح تعليم اللغــة العربيـة في إنـدونيســــا، والخطط والبرامج اللازمــة

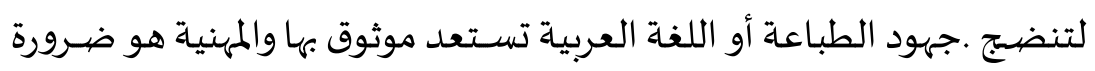
أن ليس للتفاوض لإعداد معلم اللغة العربية المهنية،

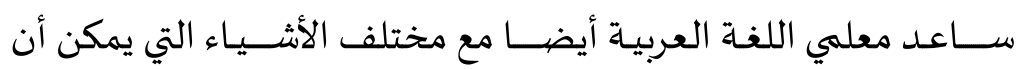

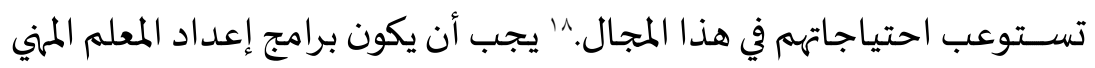

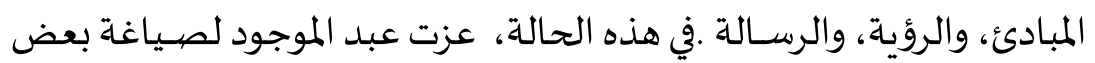

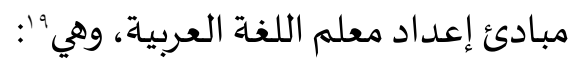

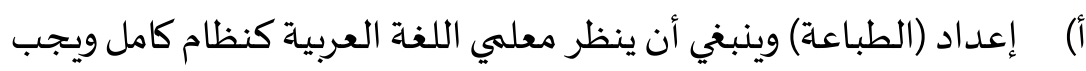

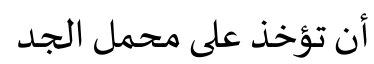

ب) برنامج إعداد أعضــاء هيئة التدريس يجب العبل العبية تشــمل ثلاثة جوانب: الجوانب الثقافية وجوانب التخصص، وجوانب هذه المهنة .

ج)سجل برنامج معلم اللغة العربية يختلف الباحثون برنامج الطباعة في اللغة وجنة الخطابية

د) يجب أن أي مؤسـســـة أو وكالة أو المدارس الإســلامية الداخلية التي تنظم برنامج إعداد معلم اللغة إئة

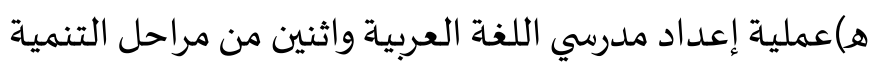

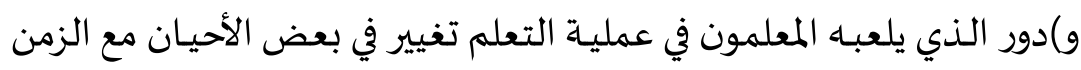
والتغيرات النظرية التي تكمن وراء تنفيذه ـ.

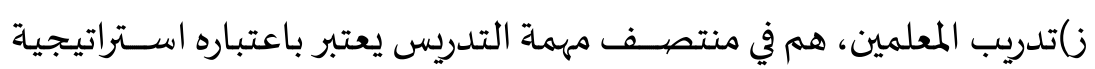
ملائمة لعملية التعليم المستمر.

18 Yasin 'Abd al-Rahman Qindil, al-Tadris wa i'dad al-mualimin (Riyadh: Wizârah al-Nasyr al- Dauli, 1993), hlm. 182

19 Izzat abdul maujud, muallim allugah alarabiyah (khurthum: 1976), hlm. 359-369. 
وفيمـا يلي قـائمـة من قـدرة المرشــحين المؤهلين ومهـارات مرة واحسدة في

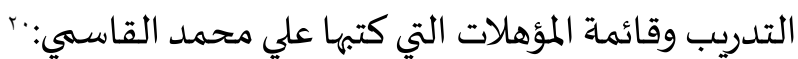

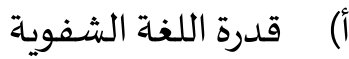

$$
\begin{aligned}
& \text { ب) القدرة في الكلام }
\end{aligned}
$$

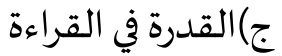

$$
\begin{aligned}
& \text { د) القدرة في الكتابة } \\
& \text { هـ) القدرة في تحليل اللغة } \\
& \text { و) القدرة في معرفة الثقافة } \\
& \text { ز) زالمعرفة والقدرات المهنية. }
\end{aligned}
$$

ع. واجبات مشرف اللغةت ومسؤوليته

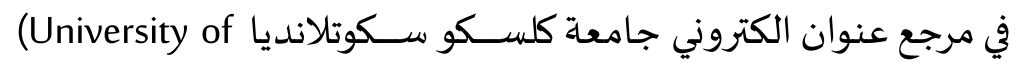

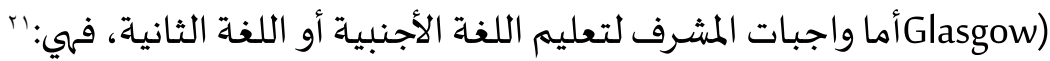

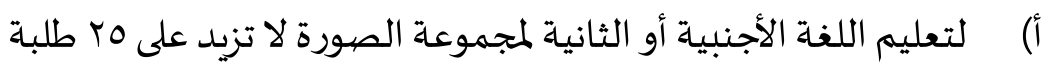

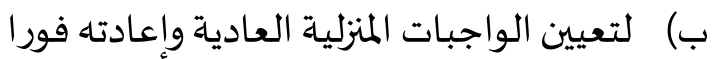

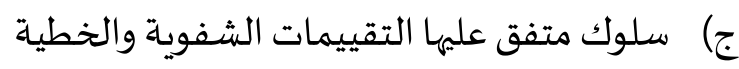
د) ل الإدارة كفاءة المعالجة المقررة ه) أن تشارك في استكمال مخرجات التعلم

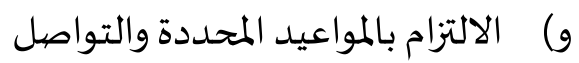
ز) للحفاظ على ما يصل إلى سجلات التاريخ و أي الحركات

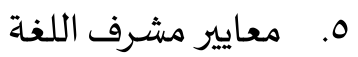

20 'Ali Muhammad al-Qasimi, ittijâhât Hadîtsah fi ta'limi lugah arabiya li natiqina bi lugah ukhra, (Riyadh: 'imadah syu'un al maktabah jamiah Riyadh, 1979), hlm. 369

${ }^{21}$ www.gla.ac.uk/media/media_204791_en, diakses pada tanggal 3 April 2016

Vol. 1, No. 2 (2019) 
Idārat Jūdat al-Ishrāfal-Lughawiy fi Tarqiyat Ta'lìm al-Lughah ...

$$
\begin{aligned}
& \text { من نفس المرجع في معـايير مشــرف اللغـة بجـامعـة كلاسـكو، لا بـد على }
\end{aligned}
$$

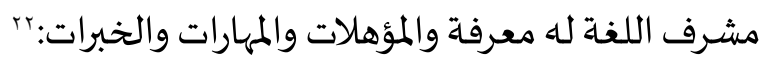

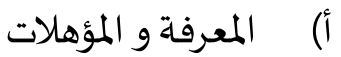

درجة أســاســية أو ما يعادلها في اللغة المطلوبة القدرة على قول (الثاني)

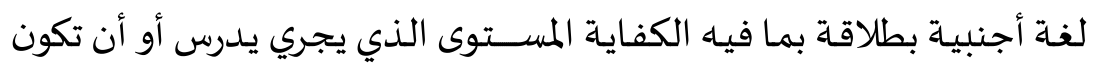

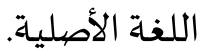

$$
\text { ب) مهارات }
$$

أسساسية كتابة والطلاقة الشفوية في اللغة التي يجري

$$
\text { أ) أهمية تعليم اللغة العربية العربية وترقيته }
$$

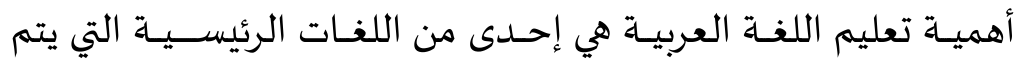

استخدامها على نطاق واسع في العالمّ. منذ في العصور الوسطى اللغة العربية

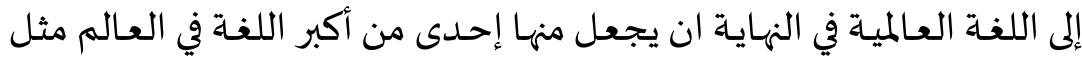

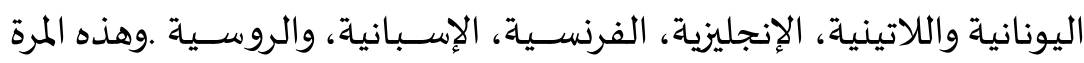
اللغة العبية هي إحدى اللغات المستخدمة لكتابة وثائق الأمم المتحدة. ب) أهداف تعليم اللغة العربية

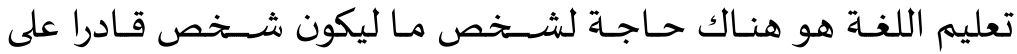

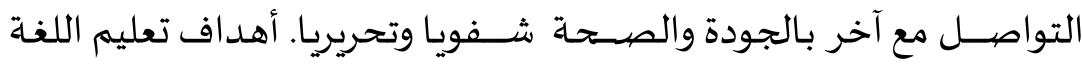
العربية هي لقدرة علوم اللغة ومهارات اللغة العربية، كمثل المطالعة، والمحادثة،

$$
\begin{aligned}
& \text { والإنشاء، والنحو، والصرف. ؛ } \\
& \text { ج) ترقية تعليم اللغة العربية }
\end{aligned}
$$

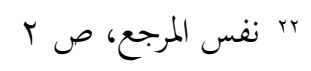

${ }^{23}$ Radliah Zainuddin, Pembelajaran Bahasa Arab, (Jakarta: Pustaka Rihlah Group, 2005), hlm. 22.

${ }_{24}$ Bustami A Gani, Al Arabiyah Bin-Namadzij, (Jakarta: PT Bulan Bintang, 1987), hlm. 16-17. 
قـال حـارس موجيمـان، أمـا لترقيـة تعليم اللغــة العربيـة، يجـب أن يهتم مشرف اللغة طرق التدريس، فهي:ro 1) (r

قـال جيرومي أســجـارو (Jerome Ascaro) ، ترقيـة تعليم في الفصــــول

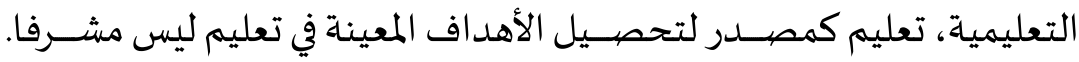
لتحصيلها هي:"

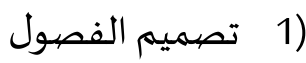

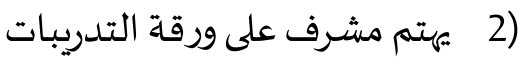
3) ع) تطبيق وتطوير إجراء الانضباط.

\section{ج. منهج البحث}

يستخدم الباحث المدخل الكيفي هو : منهجية في البحث في العلوم تركز

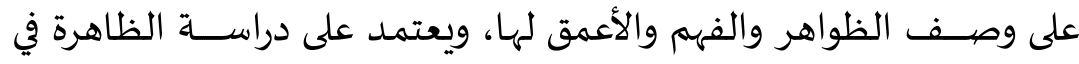
ظروفها الطبيعياة باعتبارها مصددرا مباشرا للبيانات

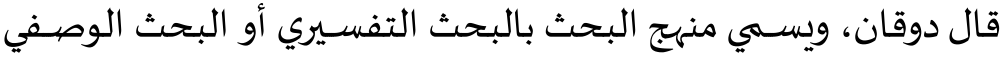
التحليلي، لأنه لايكتفي بالوصــفي فقد يتعدى ذلك للتحليل والتفسـير، وقد يسـي خاصــة في مجال دراســات العلوم الإنســانية، العمل وهناك فرق بينها

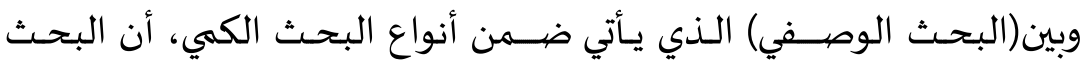

${ }^{25}$ Haris Mujiman, Manajemen Pelatihan Berbasis Belajar Mandiri, (Yogyakarta: Pustaka Pelajar,2007) Hlm 81-82

26 Jerome Arcaro, Pendidikan Berbasis Mutu Prinsip-Prinsip Perumusan dan Tata Langkah Penerapan, (Yogyakarta: Pustaka Pelajar, 2006). Hlm 48

Vol. 1, No. 2 (2019) 
Idārat Jūdat al-Ishrāfal-Lughawiy fi Tarqiyat Ta'lìm al-Lughah ...

الوصــفي يعتمد بدرجة أسـاس على الأرقام والاسـتبانات ويختلف عن البحث الكمي. الوني

يبحثث البـاحث في هـذه الكتابـة بـالمنهج الوصــفي هو طريقـة من طرق

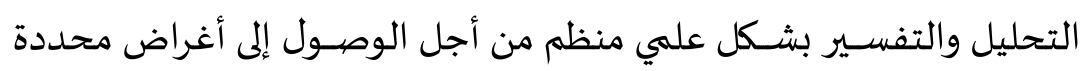

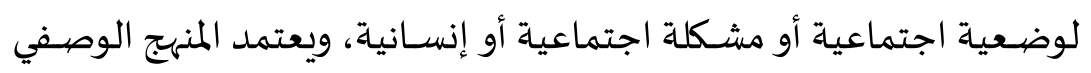

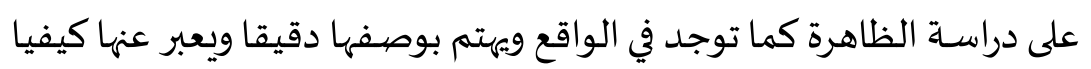

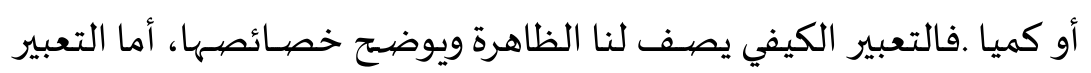

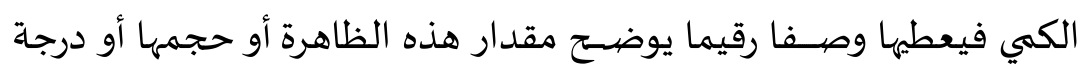
ارتبطها مع الظواهر الأخرى.

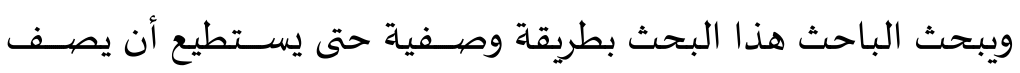

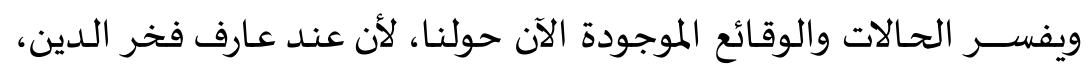

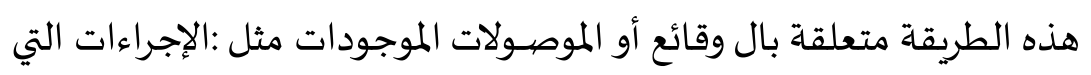

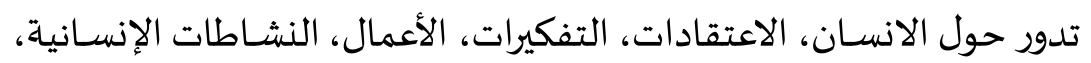

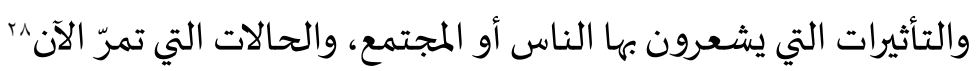

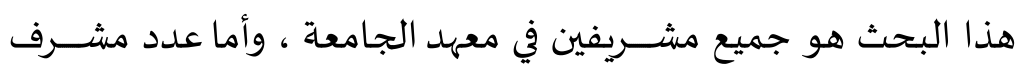

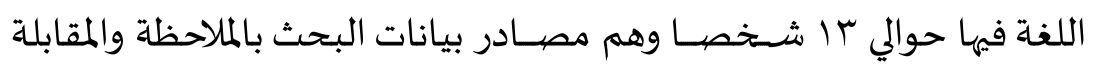

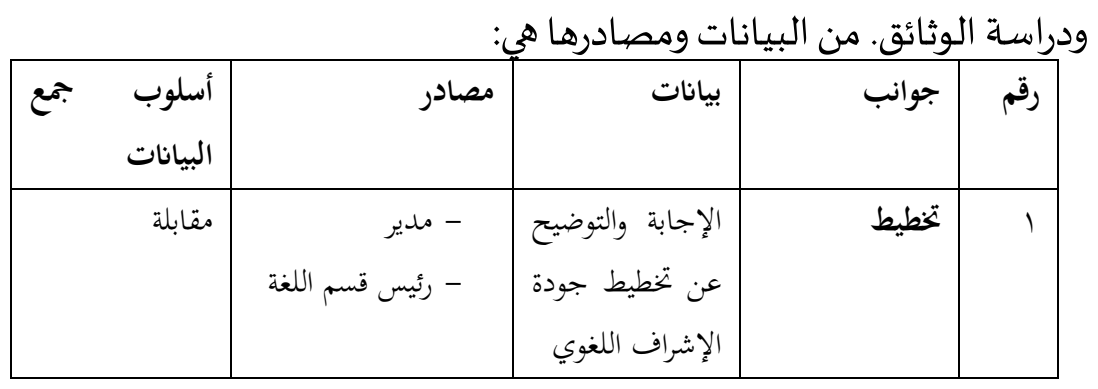

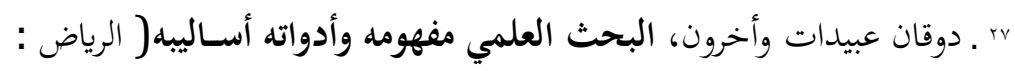

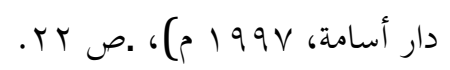

${ }^{28}$ Arif Fakhrudin, Pengantar Penelitian dalam Pendidikan , (Bandung : Pusataka Pelajar, 2007),

Hal 39-40. 
Bahroin Budiya

\begin{tabular}{|c|c|c|c|c|}
\hline مقابلة & - ـ - مئيس قسم اللغة & الإجابة والتوضيح & تنظيم & r \\
\hline مقابلة & - - مئيس قدم اللغة & شودة مشرف تنفيذ إدارة & تنفيذ & $r$ \\
\hline وثائق & - دليل/ إرشادات & & & \\
\hline مقابلة & - مدير & الإجابة والتوضيح & مراقبة & $\varepsilon$ \\
\hline ملاحظة & - - رئيس قسم اللغة & شكل مراقبة إدارة & & \\
\hline
\end{tabular}

وأســلوب تحليل البيانات، عند ماتتيو هوبرمان، تحليل البيانات هذا

البحث يشـــمل على ثلاثة عناصــر وهي تخفيض البيانات (Reduksi Data)

وعرض البيـانـات (Penyajian Data) والاســنبــاط والتحقيق -Simpulan)

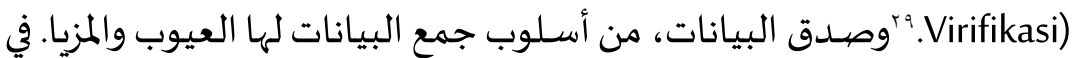

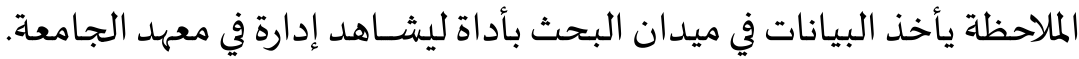

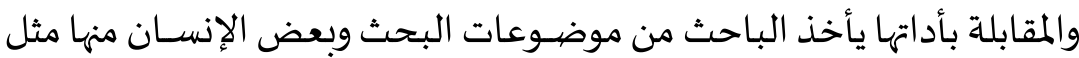
مدير المعهد، ومربي، ومشـرف اللغة. ودراســة الوثائق يأخذ الباحث وثائق إدارة

${ }^{29}$ Mattew B. Huberman A Miles, Analisa Data kualitatif: Buku Sumber tentang Metode-Metode Baru, Terjemahan Oleh Tjetjep Rohendi Rohidi, (Jakarta :Universitas Indonesia (UI) Press,1992),hlm. 16-17. 
Idārat Jūdat al-Ishrāf al-Lughawiy fi Tarqiyat Ta'lìm al-Lughah ...

جودة الإشــراف اللغوي في ترقيـة تعليم اللغـة العربيـة في معهـد جـامعـة مولانـا مالك إبراهيم الإسلامية الحكومية مالانج. د. مناقشـة نتائج البحث 1 إدارة جودة الإشراف اللغوي في ترقية تعليم اللغة العربية بمعهد الجامعة إدارة جودة الإشراف اللغوي تؤلف بها لإعطاء القيادة والمسؤولية وستكون زيادة الخبرة الواسعة. أما فوائد إدارة جودة مشرف اللغة هي: تخطيط، وتنظيم، وتنفيذ ومراقبة. والبيان كما يلي:

أ) تخطيط جودة الإشراف اللغوي في ترقية تعليم اللغة بمعهد الجامعة تخطيط إدارة جودة الإشـراف اللغوي مههم جدا في اعداده لاختيار مشـرف اللغة مناسـب لحصـول الأهداف في هذا المعهد وعملية تخطيط الذي يؤلف بـ وصــف العمل لمشــرف فيها. هذا البيان هو نفســـه كما قال مالايو هاســيبون "عملية تخطيط تبداء من الكشـفـ عن وصــف الوظيفة، وهذا تقصيـد لمعرفة

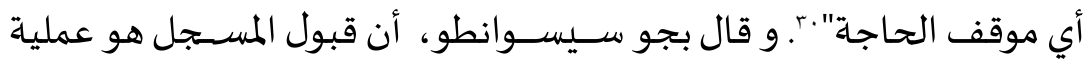
بحث الأشخخاص وتشسجيع الأمل لتسسجيل في المؤسســة.'ب وهذه العملية الأولى لقبول مشــرف اللغة بمعهد الجـامعة من جوانب مهارات اللغة والخبرة وارتباط مشرف اللغة في تعليم اللغة العربية. وأما معيار جودة الإشـراف اللغوي التي عين بها هي لدي النشــة في اللغة العربية واللغة الإنجليزية، قائمة النتيجة عالية، والشخصية الإسلامية وفاصح لقراءة القرآن من جهة علم التجويد والترجمة والتفسـير طلاقة. هذا البيان هو نفسا عن معايير اللغة التى عين بها في جامعة كلسكو سكوتلانديا University of Glasgow)

30 Malayu Hasibun, Manajemen Sumber Daya Manusia, (Jakarta: Bumi Aksara, 2000), hlm 29

31 Bedjo Siswanto, manajemen tenaga kerja ancangan dalam pendayagunakan dan pengembangan unsur tenaga kerja, (Bandung: Sinar Biru, 1989), hlm 49

${ }^{32}$ www.gla.ac.uk/media/media_204791_en, diakses pada tanggal 3 April 2016 
لمشـرف اللغة في معهد الجامعة ليس فقط فياه لدي مهارة اللغة ولكن العلوم في

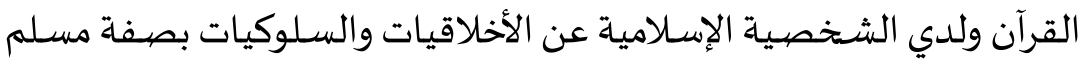
لأن هناك خلفياة الإسلام بهذه الجامعة.

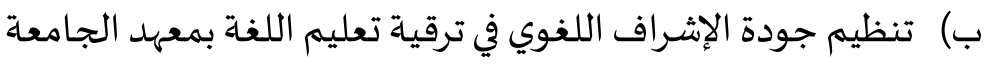
تنظيم إدارة جودة مشرف اللغة هو كيفية ينظم مشرف اللغة عن تقسيم وتصــيف الواجبات والمســؤولية لحصــول هدف تعليم اللغة العربية. وفائدة تنظيم هذه الإدارة لتصـنيف مشـرف اللغة مناسـبة قدرة ومهارات إلى الفصـول

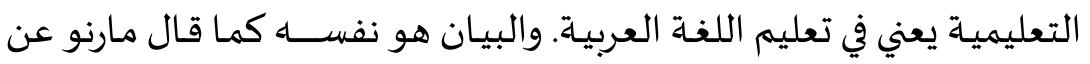

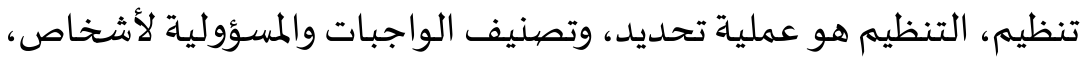

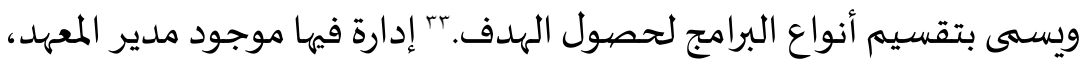
ورئيس قسم اللغة، ومربي اللغة ومشرف اللغة. وهم يعملون استمرار التنسيق.

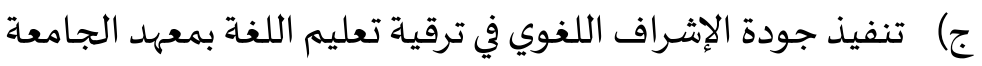
تنفيذ هو شـكل التطبيق لتحرك عناصـر من التخطيط والتنظيم. تنفيذ إدارة جودة مشرف اللغة يحاول لتطبيق بما يؤلف مدير الجامعة في التخطيط.

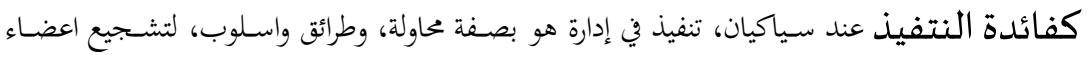

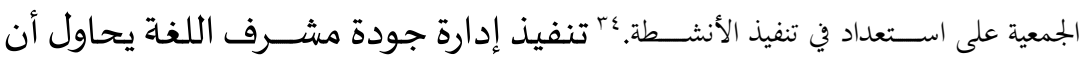
يطبق بتقديم تدريبات و برامج اللغة في معهد الجامعة. د) مراقبة جودة الإشراف اللغوي في ترقية تعليم اللغة بمعهد الجامعة مئل

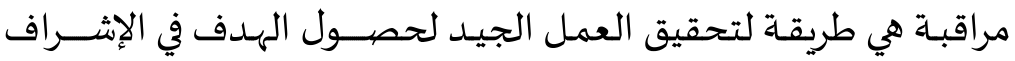
التربوي الخاص دورة مهمة في تحديد كل الهدف التعليمي الذي نفذ باه مناسبة.

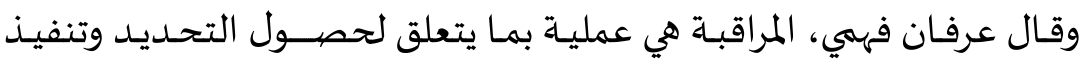

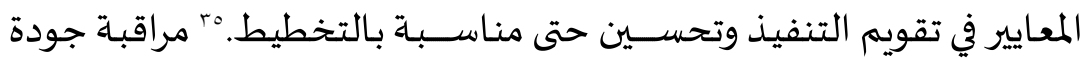

33 Marno. Dkk. Manajemen dan kepemimpinan pendidikan islam. (Bandung: PT Rafika Aditama. 2008), hlm 16

${ }^{34}$ Siagan Sondang, Fungsi -Fungsi Manajerial (jakarta: Bumi Aksara, 2007) hlm 95

35 Irfan Fahmi, Analisis Kinerja, (Bandung: Alfabeta, 2011), hlm 85 Vol. 1, No. 2 (2019) 
Idārat Jūdat al-Ishrāfal-Lughawiy fi Tarqiyat Ta'lìm al-Lughah ...

مشــرف اللغة في ترقية تعليم اللغة العربية بمعهد جامعة مولانا مالك إبراهيم الإسلامية الحكومية مالانج الذي قام باه مربي اللغة مرة واحدة في الأسبوعين. ملخص نتائج البحث ه

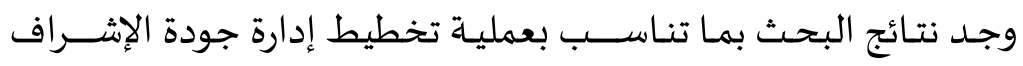

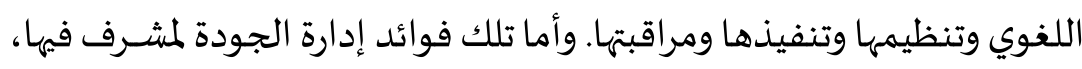
فهي:

تخطيط جودة الإشـــراف اللغوي في ترقيـة تعليم اللغـة بمعهـد الجـامعـة.

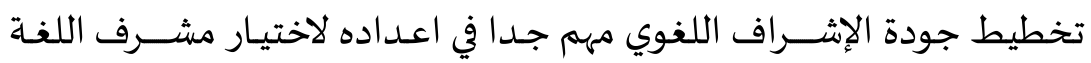

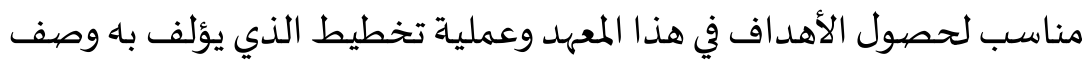

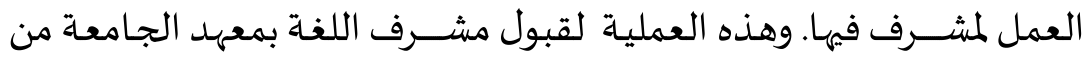
جوانب مهارات اللغة والخبرة وارتباط مشرف اللغة في تعليم اللغة العبربية. تنظيم جودة الإشراف اللغوي في ترقية تعليم اللغة بمعهد الجامعة تنظيم جودة الإشـراف اللغوي هو كيفية ينظم مشـرف اللغة عن تقسيم وتصــيف الواجبات والمســؤولية لحصــول هدف تعليم اللغة العربية. وفائدة تنظيم هذه الإدارة لتصـيف مشـرف اللغة مناسـبة قدرة ومهارات إلى الفصـول التعليميـة يعني في تعليم اللغـة العربيـة. مـدير المعهـد في دوره تخطيط دروس مده

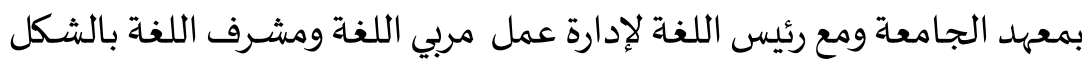

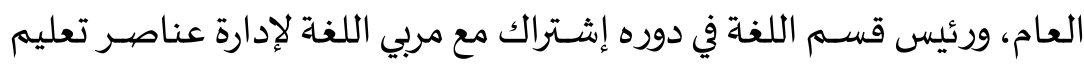

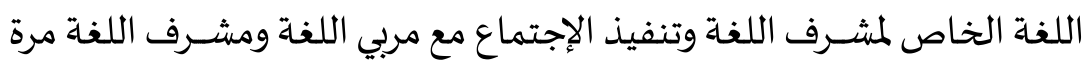
واحدة في الشـهر ومضــمون الإجتماع ملاحضـــة جودة وبصــفة تقرير لبحث ولترقية تعليم اللغة العربية الذي ادار باه. ومشــرف اللغة في معهد الجامعة في مهاجي

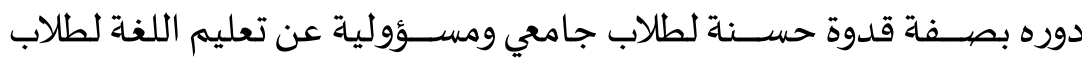

$$
\text { وبرامج اللغة آخرى. }
$$

تنفيذ جودة الإشراف اللغوي في ترقية تعليم اللغة بمعهد الجامعة 
Bahroin Budiya

تنفيذ جودة الإثـــــاف اللغوي يحاول لتطبيق بما يؤلف مدير الجامعاة في

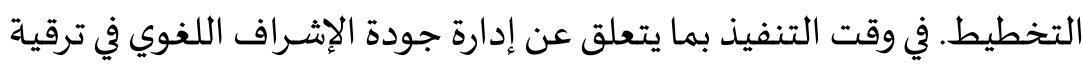
تعليم اللغة في معهد الجامعة، يحقق مجلس اللغة لترقية تعليم اللغة العربية

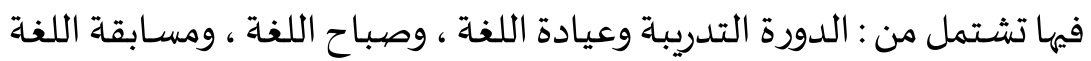
، ومركز اللغة وندوة ثنائي. مراقبة جودة الإشراف اللغوي في ترقية تعليم اللغة بمعهد الجامعة مراقبة جودة الإشـراف اللغوي في ترقية تعليم اللغة العربية بمعهد جامعافة

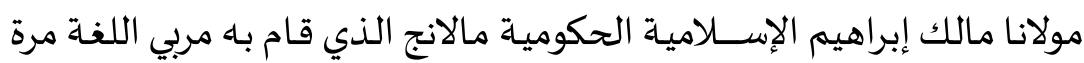

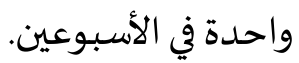

\section{قائمة المراجع}

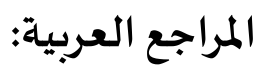

إبرهيم أنيس وآخرون، المعجم الوسيط، الطبعة الرابعة، المجلد الثاني،

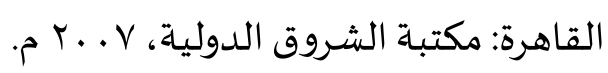

أحمد الحمد، التربية الإسلامية، الطبعة الأولى، الرياض: دار اشبيليا لنشر

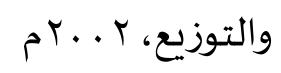

جودت الركابي، طرق تعليم اللغة العبية، الطبعة العاشرة ،دمشق:

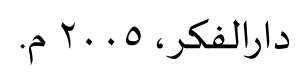

دوقان عبيدات وأخرون، البحث العلمي مفهومو وأدواتو أساليبو، الرياض : دار أسامة، عاندان

يس عبد الرحمن، التعليم وإعداد المعلم، الطبعة الثانية، الرياض: دار النشر

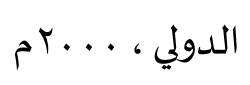


Idārat Jūdat al-Ishrāfal-Lughawiy fi Tarqiyat Ta'lìm al-Lughah ...

محمد علي الخولي، أساليب تدريس اللغة العربية، الطبعة الأولى،

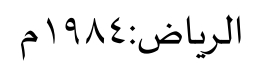

مدحت محمد أبو النصر، الأداء الإداري المتميز، المجموعة العربية للتدريب

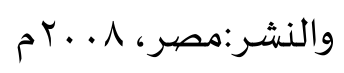

مسعد محمد زياد، التدريب التربوي للمعلمين :التعليم الأساسي -التعليم

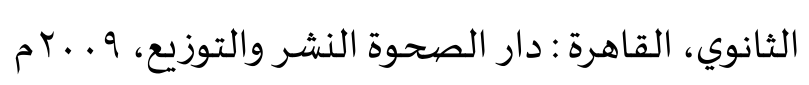

عبد الرحمن إبراهيم الفوزان، إضاءات لمعلمي اللغة العربية لغير الناطقين

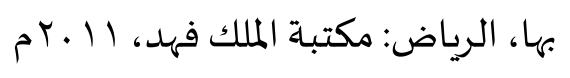

عبد الرحمن أحمد عثمان، مناهج البحث العلمي وطرق كتابة الرسلة

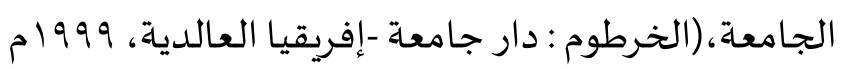

فريد النجار، إدارة الجودة الشـاملة والإنتاجية والتخطيط التكنولوجي للتميز

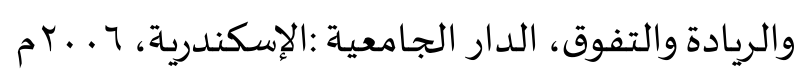

فايز بن عبد الكريم، دور المعلم في تربية الطلاب، الطبعة الأولى . بع اهـ له محمد أحمد السيد، اللغة تدريسا واكتسابا، الطبعة الأولى، الرياض: دار

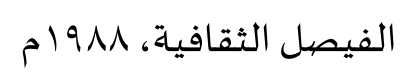

خالد سعد الجضعي ، الإدارة : النظريات والوظائف ، الطبعة الأولى ، IV ه

راتب السعود، الإشراف التربوي مفهومه ونظرياته وأساليبه، ، الطبعة الثانية، :

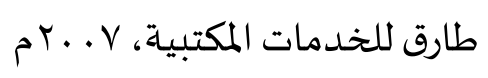

رياض رشاد البنا، إدارة الجودة الشاملة، مقدمة إلى المؤتمر السنوي الواحد

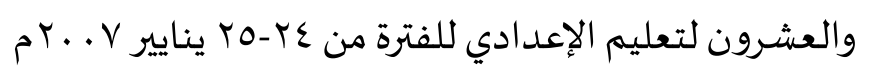


Abd al-Rahman Qindil, 1993.Yasin, al-Tadris wa i'dad almualimin Riyadh: Wizârah al-Nasyr al- Dauli

A Gani , 1987. Bustami, Al Arabiyah Bin-Namadzij, Jakarta: PT Bulan Bintang,

Arikunto, Suharsimi, 1998. Prosedur Penelitian, Suatu Pendekatan Praktek, Jakarta : PT. Rineka Cipta

Arcaro, Jerome, 2006 Pendidikan Berbasis Mutu PrinsipPrinsip Perumusan dan Tata Langkah Penerapan, Yogyakarta: Pustaka Pelajar

Bahruddin, Uril. 2010. Tathwîr Manhaj Ta'lîm al-Lughah al'Arabiyyah (Malang: UIN Maulana Malik Ibrahim Malang Press

Efendi Hariadja, 2002. Marihot, Manajemen Sumber Daya Manusia: Pengadaaan, pengembangan, pengkompensasian dan peningkatan produktifitas karyawan, Jakarta: PT Gramedia Widiasarana Indonesia

Fahmi, Irfan, 2011. Analisis Kinerja, Bandung: Alfabeta

Fakhrudin, Arif, 2007. Pengantar Penelitian dalam Pendidikan, Bandung : Pusataka Pelajar

Hasibun. Malayu, 2000. Manajemen Sumber Daya Manusia, Jakarta: Bumi Aksara,

Huberman A Miles, Mattew B. 1992. Analisa Data kualitatif: Buku Sumber tentang Metode-Metode Baru, Terjemahan Oleh Tjetjep Rohendi Rohidi, (Jakarta :Universitas Indonesia (UI) Press

Idrus, Muhammad, 2009. Metode Penelitian Ilmu Sosial Pendekatan Kualitatif dan Kuantitatif, Jakarta: Erlangga 
Idārat Jūdat al-Ishrāf al-Lughawiy fi Tarqiyat Ta'lìm al-Lughah ...

Jones, James j, \& Walters, Donald. 2008. Human Resource Manajement in Education. Sleman Yogyakarta: Q-Media

Minarti, Sri, 2011. Manajemen Sekolah, Yogyakarta : Ar-ruzz media

Marno. Dkk. 2008. Manajemen dan kepemimpinan pendidikan islam. Bandung: PT Rafika Aditama

Maujud, Izzat abdul. 1976. muallim allugah alarabiyah khurthum

Moleong, Lexi J, 2000. Metodologi Penelitian Kualitatif, (Bandung : PT. Remaja Rosdakarya

Mulyasa, E, 2005. Menjadi Kepala Sekolah Professional dalam Mensukseskan MBS dan KBK, Bandung: PT. Remaja Rosdakarya

Nurjana, Nana, 2000. Dasar-dasar Proses Belajar Mengajar, Bandung : Sinar algesindo

Sallis, 1993. Total Quality Management In Education, London: Kogan Page Education Management Series

Siswanto, Bedjo, 1989. manajemen tenaga kerja ancangan dalam pendayagunakan dan pengembangan unsur tenaga kerja, Bandung: Sinar Biru

Sondang, Siagian. 2007. Fungsi -Fungsi Manajerial. jakarta: Bumi Aksara

Sugiono, 2011. Metode Penelitian Kualitatif, Kuantitatif dan R\&D, (Bandung: Alfabeta

Syani, Abdul, 1987. Manajemen Organisasi surabaya: Bina Aksara

Usman ,Husaini, 2008. Manajemen Teori Praktik \& Riset Pendidikan, Jakarta: Bumi Aksara 
Zainuddin, Radliah, 2005. Pembelajaran Bahasa Arab, Jakarta: Pustaka Rihlah Group

Hendayana, Sumar. Dkk. 2007. Lesson Study Suatu Strategi untuk Meningkatkan Keprofesionalan Pendidik - Pengalaman IMSTEP-JICA. Bandung: UPI Press

Muhaiban. 2006. 'Al-lughah al-'Arabiyyah fi Indunisiya: Dirasah Ta'liliyyah 'an Tatawwuratiha wa Musykilat Ta'limiha'. Jurnal Studia Islamika UIN Sunan Kalijaga Yogyakarta

Khoirul Adib, Makalah disampaikan dalam Pelatihan Peningkatan Keprofesionalan Guru Bhs Arab http://sastra.um.ac.id/?p=964 diakses tanggal 22 Nopember 2015

Alwanis, http://www.lakii.com/vb/a-88/a-124686/, diakses pada tanggal 13 januari 2016

www.gla.ac.uk/media/media_204791_en , diakses pada tanggal 3 April 2016 
THIS PAGE INTENTIONALLY LEFT BLANK 